\title{
Policy Stability in Climate Governance: The Case of the United Kingdom
}

\begin{abstract}
'Super-wicked' problems such as climate change require ambitious policies within stable policy frameworks. Key for policy stability is to disincentivise future reversals to carbon-intensive lifestyles resulting in unstoppable climate change. It requires lockin into a low-carbon development trajectory, increasing popular support and needs to be self-reinforcing with reversal costs rising over time as benefits increase. In parliamentary political systems (e.g. UK), policies emerge more easily but are more difficult to maintain given that shifting political majorities can result in policy Uturns, resulting in uncertainties for investment in low-carbon transitions. We examine what factors determine policy stability in UK Climate Change Policy aiming to reduce $\mathrm{CO}_{2}$ emissions by $85-90 \%$ by 2050 . Policy stability depends on favourable public opinion and the political system. In the case of parliamentary democracies the extent to which it is embedded into a multilevel governance institutional framework and political cross-party consensus is particularly important for policy stability.
\end{abstract}

Keywords: Climate policy, public opinion, political system, climate governance, policy stability 


\section{Introduction}

'Super-wicked' problems such as climate change require ambitious and stable policies (Levin et al., 2012). To address climate change effectively, considerable upfront investments into $R \& D$, technology, changes to business models and infrastructure are necessary. One key impediment for such investments is policy uncertainty. This means that for low carbon investments to be viable and pay off in the long term, investment-incentivising policies must remain stable and reliable over their life-span and pay-off period of frequently over 20 years, pointing towards a crucial importance of stable, predictable government investment (Liang and Fiorino, 2013) and policy frameworks. Key areas requiring significant investments are renewable energy (Favretto et al., 2015), green urban infrastructure (Smedby and Quitzau, 2016) and adaptation (Wamsler, 2016). Sticking to a policy pathway is central for stable policies. This increases the confidence of all stakeholders that their behavioural changes and investments into corresponding compliance activities will be rewarded over the longer term (Koch et al. 2009).

This analysis contributes to the policy stability literature. It addresses the challenge that short-term changes in government may result in derailing concerted, democratically legitimated national and global efforts to address cross-border and intergenerational challenges such as climate change, environmental degradation and ensuring sustainable development. There is an increasing number of examples of fading political support for environmental and climate change policies, even among lauded 'leaders' such as Sweden (Hysing, 2014), and across developed countries, especially in the European Union. This is part of an emerging trend of environmental 'policy dismantling', i.e. rolling back the policy advances made in the 1990s and 2000s in the wake of ongoing economic austerity measures (Gravey and Jordan, 2016). This poses a direct challenge to the need for stable policies that facilitate investment in clean technologies and help implement the Paris Agreement. An increasing body of policy literature argues in favour of policy interventions that allow effectively addressing climate change and analysing options of achieving this objective (e.g. Jordan and Matt, 2014; O’Neill et al., 2013). This is especially important in policy areas dealing with 'super-wicked' problems such as climate 
change, which are defined as "time is running out; those who cause the problem also seek to provide a solution; the central authority needed to address them is weak or non-existent; and irrational discounting occurs that pushes responses into the future” (Levin et al., 2012: 124).

The central claim of this paper is that policy stability can achieve an upward virtuous cycle of policies that support and reinforce sustainable development. The central research question is: Which framework conditions are relevant to design and maintain stable and ambitious policies capable of addressing 'super-wicked' problems such as climate change? This contribution focuses on the framework conditions that enable policy stability, i.e. helping policies to stay in place to address particularly difficult long-term problems. The concept of path-dependency as an element of policy stability can be used to strengthen policies that address collective action problems of public goods (Levin et al., 2012). The central contribution is to address the gap in the literature regarding the design of stable policies by illustrating how policy stability depends on a favourable public mood, and on the political system. In a presidential political system it is difficult for policies to emerge when different parties control the legislative and executive (e.g. climate change in the United States if executive orders are not taken into account), but it is also more difficult to dismantle them following an election, compared to parliamentary systems where the victorious party controls both executive and legislative. A key finding of this article is that in the case of parliamentary democracies the extent to which public policymaking is embedded into a multilevel governance framework and political cross-party consensus are crucial for policy stability.

Following a discussion of these factors, this article proceeds to an empirical analysis of UK Climate Change Policy, based on the 2008 UK Climate Change Act. This was identified as a most-likely case of a potentially stable climate policy based on a review of over 500 climate laws in 66 countries (Nachmany et al. 2014) due to its long-term policy design towards 2050 and carbon budgets. The analysis draws on data from a 2010 survey of public pereceptions of climate change in the UK. A unique probit analysis is conducted of a sub-set of data from this survey, finding that levels of concern play a positive and significant role in shaping willingness to take public action on climate change amongst individuals, and that climate change beliefs 
were not a significant driver of voting preferences in UK elections. These findings combine to highlight the opportunties to seize upon periods of high levels of concern to implement policy, and the ability to build cross-party consensus on the issue. The analysis also examines the evolution of concern for climate change in the UK via Eurobarometer surveys, illustrating that declines in public concern were not associated with dramatic changes in UK climate change policy. The findings demonstrate the opportunities and political pitfalls to policy stability and will be critically discussed in the fourth section before the fifth section concludes on the findings.

\section{Conditioning factors for policy stability}

The policy dismantling literature offers a very useful point of departure. It made important contributions to the study of environmental policy with its focus on intentionally, actor-driven policy change on the EU level (Gravey and Jordan, 2016) and policy output in terms of dismantling by default, arena-shifting, symbolic action and active dismantling (Bauer et al., 2012). The following section draws attention to factors that condition the choices of actors to achieve policy stability. Subsequently, policy stability is defined as maintaining the status quo of a policy and strengthening it over time as opposed to weakening and/ or dismantling a policy. This points towards institutional conditions that can avoid or at least offer a barrier towards unintentional policy dismantling, which puts long-term policies, such as on climate change, at risk of becoming 'collateral damage' in times of economic austerity and shifting political attention towards economic and security challenges. The following analysis identifies and discusses public opinion and the political system as factors that can either support or weaken policy stability. These have been rarely systematically examined in the policy change literature, which so far has focused, pre-dominantly, on actor's interests and power constellations between advocacy coalitions, the availability of policy solutions looking for a policy problem, the role of policy entrepreneurs, windows of opportunity and the impact of external shocks (Baumgartner et al., 2009; Kingdon, 1995; Sabatier, 1998). Our contribution seeks to 
illustrate the relevance of public opinion and the political system as conditioning factors within major theories of policy change.

\section{Path-dependency}

The concept of path-dependency can be useful to understand and reduce the likelihood of policy U-turns following a change in political leadership or short-term shocks to the political system in other policy areas. So far, most of the literature on socio-technological change and policy analysis focused on negative or unintended consequences of policies that, shortly after their development, became very costly to reverse with an increasing constituency of beneficiaries, who formed a strong lobby against policy reform (Mahzouni 2015). Thus, negative effects of that policy were 'locked-in' to remain in place. The best-known effects of technological lock-in and social path-dependencies are the QWERTY-keyboard, the design of the combustionengine, the lock-in into a carbon intensive lifestyle based on the built infrastructure and behavioural path-dependencies such as consumption habits (Barnes et al., 2004). A rich literature developed around the sources, negative effects and barriers to overcoming such path-dependencies in technological developments and economic transformations (e.g. Berkhout, 2002; Foxon, 2013). It illustrates the pitfalls of pathdependency and illustrates why path-dependency, i.e. the self-reinforcing character of a policy-pathway, is traditionally seen as normatively undesirable feature of policy outcomes. This is however only one (albeit dominant) side of the coin.

This contribution embraces the more recent and less explored constructivist perspective that path-dependency is what actors make of it, thus also allowing for normatively desirable and stable policies to emerge and to be adapted to unforeseen changes within a pathway. This basic assumption adopted from Levin, Cashore, Bernstein and Auld (2012) can offer a useful concept to 'constrain our future selves' to a low-carbon economic development pathway and to avoid future reversals to carbon intensive lifestyles that would result in unstoppable and catastrophic changes to the earth system. Levin et al. (2012) suggest four preconditions for policies to be regarded as path-dependent and thus capable of addressing 'super-wicked' problems such as climate change: (1) lock-in of the policies via an immediate durability of the 
policy design, e.g. via institutional rules creating hurdles making it immediately hard to reverse the policy, such as constitutional provisions or consensus voting; (2) the policy needs to contain self-reinforcing dynamics by increasing the costs of reversing the policy over time, such as creating vested interests of actors who expect their investments to pay-off in the future and who would be opposed to reversing the policy; (3) increasing returns of policy benefits over time and (4) scope for positive feedbacks via expanding to other populations and reinforcing the support of the original target population.

There is a downside to lock-in effects if a policy gets locked into a pathway that turns out to be highly counterproductive to the initial objective. This includes among others changes to the framework conditions, new technological developments or new scientific evidence. Policies can fall victim to their initial success based on weak ambitions to achieve a high acceptability among key stakeholders such as industry. If these industries however make long-term investments based on their expectations of continuing weak policy ambitions and lobby policymakers accordingly to prevent more ambitious policy reforms, policies can become locked into 'low-ambition' pathways that turn out to be contrary to their initial motivations of effectively addressing climate change. For example, the EU Emission Trading Scheme (ETS) was introduced using a phased approach (Skaerseth and Wettestad, 2009). To reduce opposition the initial pilot phase between 2005-2007 had weak targets and was self-contained. The subsequent two phases have also suffered from unambitious targets and low carbon prices, reducing the long-term incentives to invest in low-carbon energy generation in Europe.

Thus, a path-dependent policy also needs to be adaptable via in-built flexibility of a policy pathway to allow for adjustments of the policy details while the overall policy pathway remains stable. Therefore, we add adaptability within a pathway and the possibility to revise a pathway towards higher ambitions (in line with the original policy objective) as fifth criterion for policy stability. This is particularly important to allow adjustments to the policy details over time as new scientific evidence becomes available calling for stronger or allowing weaker policy measures, technological advancements making alternative low carbon approaches more economically feasible or negative social, economic or environmental consequences of 
one pathway call for alternative approaches. Such adaptability is one major achievement of the 2015 Paris Agreement with its automatic five-yearly review cycle of domestic climate policies. This alignment of policy measures with roadmap targets provides further tools to readjust policies. The five criteria for policy stability are widely applicable to different country contexts and environmental policy related fields. However, there are certain conditioning factors that make it more or less likely for countries to reduce the chance of reversibility of policy change in support of a stable environment for low carbon technology investments. These must be taken into account when assessing policy stability based on the five criteria discussed above.

Broadly, they can be differentiated as institutional and socio-political conditioning factors of agency in policymaking. The major agents in democratic decisionmaking are political parties, politicians and the electorate, whose activities are guided by (country specific) rules, norms, civil society and increasingly social media. This points towards the political system and public opinion as major conditioning factors for stable policies to emerge and persist.

\section{The political system: multilevel governance and party-political consensus}

Why are some countries successful in designing and maintaining climate policies while others experience U-turns? Key examples are Germany's three U-turns on nuclear energy (phase-out, continous use with new government in 2009, phase-out due to strong public opposition following the 2011 Fukushima disaster) and the reversion of the Australian Carbon Tax and Emission Trading Scheme, which was introduced via the Clean Energy Act 2011. Following Tony Abbot's LNP victory in the general election 2013, the Clean Energy legislative package and with it the carbon tax and emission trading scheme were repealed in 2014 and replaced by weaker climate legislation (Nachmany et al., 2014). At the same time, the US still define most of their climate change policy via the 1963 Clean Air Act as well as its 1970 extension and 1977/1990 amendments (Nachmany et al. 2014: 606). This illustrates that in parliamentary systems such as Australia, new policies are quick to emerge, but can also be repealed easily. The presidential political system with frequently opposing majorities in the House of Representatives and/or US Senate makes it very difficult 
for policies to emerge, but also difficult to be removed once they are in place (Levin et al., 2012).

These examples indicate that the political system and political voting behaviour (Carey and Hix, 2011) are relevant factors for policies to emerge and be reversed, i.e. both matter for stability and adaptability. The separation of powers, e.g. in a presidential system (Bell 2004) such as the US, or a sharing of powers e.g. in parliamentary systems (such as Australia, Germany, UK) as well as the impact of proportional voting (Vowles 2004) versus 'first-past-the-post' systems (Kedar 2011) can influence how easily a policy outcome can be achieved following debates and votes in the legislature. This in turn can also determine how easily the next government can change policies enacted by the previous government. Yet, where and when a countries' constitution emerged also determines details of the electoral system.

Thus, the design of the political system and its influence on legislative voting behaviour plays an important role in widening or limiting policy options in more controversial policy environments. An exception would be the existence of a strong party-political consensus, which can help to keep windows of opportunity for policy change open for a longer period of time. Powerful 'winning coalitions' succeed in policymaking with their proposals when the positions of relevant actors shift gradually towards an equilibrium between the group's interests (Bernstein and Cashore, 2007). The second aspect is how strongly a country is embedded into multilevel governance arrangements. These include multilateral agreements such as the Kyoto Protocol and the Paris Agreement on the international level and, in the case of EU countries, regional-level burden sharing agreements within multilevel environmental governance (Balme and Ye 2014; Paavola 2016) and implementation of EU climate change policy into national law. This multilevel governance aspect requires the implementation of global commitments and limits governments' ability to easily modify (or repeal) existing climate change policies. 


\section{Public opinion}

Public opinion and the wider 'national mood' can extend or limit the options available to policymakers. The 'national mood' is the public's awareness of a policy problem disseminated via the media. Strong public opinion and concern about a policy issue can provide justification and reassurance for politicians to act (Kingdon, 1995). Public opinion is thus relevant for elections, re-election and determining public willingness to accept for example climate and environmental policies. Furthermore, public opinion is not only influenced by government action, it also signals policymakers initial and sustained public support for a policy, which is extremely important for stable policies that once in place are designed to be 'sticky' and difficult to reverse. Yet, stable policies also depend on the policy options that were available at a specific point in time. These policy options were formed based on the interests of key actors and the overall 'national mood' communicated to policymakers via the media and opinion polls.

The 'national mood' links the available policy options to the key actor's political interests, which are determined by beliefs, values, agendas, party ideology and pressure group campaigns. These evolve over time. It is relevant for policymakers as it reflects wider societal demands and the thinking of a large number of individuals along common lines. It creates an initial openness to ideas among policymakers, whose "sense of the national mood serves to promote some items on their policy agendas and restrain others from rising to prominence” (Kingdon, 1995: 147). External shocks can influence the 'national mood' such as the nuclear disaster in Fukushima in March 2011 that led to Germany’s exit from using nuclear power, or unusually intensive heat waves and hurricanes that are associated with accelerating climate change such as Hurricanes Katrina in 2005 and Sandy in 2011. Depending on how the media frames these issues, they can impact on public opinion (Brandenburg and Van Egmond, 2011), ultimately shifting policy preferences.

This section discussed the relevance of public opinion and the political system as relevant conditioning factors for stable policies capable of effectively addressing climate change and other 'super wicked' policy problems. It thus addresses a rarely explored aspect of central public policy theories concerned with policy change (Baumgartner et al., 2009; Kingdon, 1995; Sabatier, 1998) by highlighting conditions 
for policy stability with scope for minor adaptability of policy pathways to take into account changing circumstances while still increasing policy actions that address the initial 'super wicked' policy problem. The following section illustrates the relevance of public opinion and the political system for policy stability through the empirical example of UK climate change policy between 2006 and 2013 with a focus on the 2008 Climate Change Act. The section serves two purposes. First, it empirically illustrates that public opinion and the policy system do indeed matter for policy stability and should thus be taken into account in analyses of policy change and stability. Second, it offers insight into the relationship between these two conditioning factors and the factors determining policy change highlighted by major policy change theories.

\section{Methodology}

The UK Climate Change Policy case study draws from the analysis of policy documents, the academic literature, media reports and public opinion surveys (Pidgeon et al., 2010). The first survey was based on a nationally representative faceto-face interviews with 1822 responses conducted by Ipsos MORI in 2010 for the study "Public perceptions of climate change and energy futures in Britain 2010" (Pidgeon et al., 2010) based at the University of Cardiff, funded by the British Economic and Social Research Council (ESRC) and retrieved via the University of Essex UK Data Archive. The year 2010 was an ideal time to conduct such a survey on the willingness of the UK public to accept climate change policies. The 2008 Climate Change Act was beginning to take effect after climate change emerged as a major issue on the political agenda and in the media. Al Gore's documentary 'An Inconvenient Truth', the Stern Review on the costs of climate change and the 2009 Climate Change summit in Copenhagen coincided with high media coverage and public awareness of climate change between 2007 and 2010 (Gifford et al. 2016). Yet it also captures disappointment at international difficulties and economic challenges of the emerging austerity government agenda. This suggests that survey respondents 
were able to make educated judgements about climate change and had an awareness of the pros and cons associated with climate change policy.

In the first model the independent variable is the categorical question on public concern on climate change while the dependent variable, which is also categorical, is on the public's willingness to accept stable, far-reaching climate mitigation policies and was measured via the respondent's likelihood to vote in favour of the government spending "taxpayer's money on British projects designed to tackle climate change” coded in the survey as question Q38_4 (Pidgeon et al. 2010). The analysis is based on ordered probit models in STATA. Ordered probit models were chosen as they are appropriate for categorical dependent variables for which other estimation techniques, such as Ordinary Least Squares, would offer biased results. A second separate ordered probit is then run that examines the effect of political belief as a determinant of concern. The conceptual model tested is that concern for climate change is the key determinant of public willingness to accept policy, and that concern is in turn determined by politics. The probit models are represented by the standard equation given in (1), where $\Phi$ is the normal distribution:

$$
P\left(y_{i}=1 \mid x\right)=\Phi\left(x_{i}{ }^{\prime} \beta\right)(1)
$$

In the first model the dependent variable, $\mathrm{y}_{\mathrm{i}}$, is the likelihood to vote for government policies to implement climate change policies, while the covariate $x_{i}$ is the concern for climate change. In the second model the dependent variable $\mathrm{y}_{\mathrm{i}}$ is the concern regarding climate change, and $\mathrm{x}_{\mathrm{i}}$ is a set of covariates in the category politics.

\section{Evaluating policy stability in UK Climate Change Policy}

This section illustrates the relevance of public opinion and the political system for policy stability at the example of UK Climate Change Policy. The 2008 Climate Change Act (Lockwood, 2013) and a package of related policies such as the Low Carbon Transition Plan 2009 increased ambitions compared to previous policies and set out a pathway towards $\mathrm{CO}_{2}$ emission reductions using carbon budgets, command- 
and-control and market-based policy instruments. It established the world's first legally binding national climate mitigation target (Nachmany et al., 2014). Following the Paris Agreement on Climate Change with its five-yearly review cycle of national climate policies and the objective to decarbonise economies by the end of the century, the UK Climate Change Act is likely to be seen as potential policy role-model by other developed countries as it provides an early empirical example of relatively ambitious climate policy.

The flagship legislation includes the Green New Deal/ Energy Act 2011 to improve energy efficiency in buildings (Booth and Choudhary, 2013), the 2010updated building regulations part L on energy efficiency improvements, Supplier Obligations/ updated Carbon Emission Reduction Targets, tax breaks for low emission vehicles, the CRC Energy Efficiency Scheme 2013 and an increased focus on renewable energies and Carbon Capture and Storage. The climate policies legislated between 2000 and 2013 aim at incentivising low carbon lifestyles.

\section{Public opinion: concern about climate change and willingness to accept policies}

There is a generally wide acceptability and support for climate policies among the public, including a willingness among the majority to pay for higher electricity bills linked to investments in renewable energies and energy efficiency (Pidgeon et al., 2010). 71 per cent of respondents (strongly) agree that it is their responsibility to help do something about climate change. 68 per cent would vote in favour of spending taxpayer's money on British projects designed to tackle climate change, while 65 per cent (strongly) agree that they are prepared to greatly reduce their energy use to help tackle climate change. 52 per cent are willing to pay up to $£ 10 / \$ 15$ more per month on their energy bills to ensure that electricity comes primarily from renewable sources (Pidgeon et al., 2010).

The results for the willingness to vote for public action on climate change show that increasing concern is positively and significantly related to willingness to 
take action (Table 1). The scale of the marginal effects can be seen in Table 2. Those who are fairly concerned with climate change are 3 per cent more likely to definitely vote against policies than those who are very concerned, and 15 per cent less likely to definitely vote in favour. Those who are not at all concerned are 21 per cent more likely to definitely vote against, and 36 per cent less likely to definitely vote in favour. These results highlight that concern plays a crucial role in shaping willingness to take public action on climate change.

\begin{tabular}{|l|l|}
\hline & $\begin{array}{l}\text { Ordered probit coefficient - } \\
\text { Public action Q38_4 }\end{array}$ \\
\hline Q8_2 - Fairly concerned & $-0.383^{* * *}$ \\
& $(-6.52)$ \\
& $(0.00)$ \\
\hline Q8_3 - Not very con- & $-0.707^{* * *}$ \\
cerned & $(-9.61)$ \\
& $(0.00)$ \\
\hline Q8_4 - Not at all con- & $-1.209^{* * *}$ \\
cerned & $(-13.01)$ \\
& $(0.00)$ \\
\hline Q8_5 - Don't know & -0.344 \\
& $(-1.16)$ \\
& $(0.245)$ \\
\hline Q8_6- No opinion & -0.578 \\
& $(-1.50)$ \\
& $(0.135)$ \\
\hline N & 2073 \\
\hline Pseudo-R & 0.0408 \\
\hline
\end{tabular}

Table 1. Ordered probit coefficients of concern on climate change (Q8) and likelihood to vote in favour of the government spending taxes to address climate change (Q38_4) Base question Q8_1 - Very concerned. Compiled by authors. ${ }^{1}$

\begin{tabular}{|l|l|l|l|l|}
\hline $\begin{array}{l}\text { Q38_4 } \\
\text { Willingness to } \\
\text { vote for gov- } \\
\text { ernment spend- } \\
\text { ing taxpayers } \\
\text { money }\end{array}$ & $\begin{array}{l}\text { Ordered probit } \\
\text { marginal effects } \\
\text { for 'definitely } \\
\text { vote against' }\end{array}$ & $\begin{array}{l}\text { Ordered probit } \\
\text { marginal effects } \\
\text { for 'probably } \\
\text { vote against' }\end{array}$ & $\begin{array}{l}\text { Ordered probit } \\
\text { marginal effects } \\
\text { for 'probably } \\
\text { vote in favour' }\end{array}$ & $\begin{array}{l}\text { Ordered probit } \\
\text { marginal effects } \\
\text { for 'definitely } \\
\text { vote in favour' }\end{array}$ \\
\hline $\begin{array}{l}\text { Q8_2-Fairly } \\
\text { concerned }\end{array}$ & $0.034^{* * *}$ & $0.061^{* * *}$ & $0.050^{* * *}$ & $-0.145^{* * *}$ \\
& $(6.06)$ & $(6.53)$ & $(5.34)$ & $(-6.51)$ \\
$(0.00)$ & $(0.00)$ & $(0.00)$ & $(0.00)$ \\
\hline Q8_3 - Not very & $0.083^{* * *}$ & $0.119^{* * *}$ & $0.047^{* * *}$ & $-0.250^{* * *}$ \\
concerned & $(7.14)$ & $(9.12)$ & $(4.71)$ & $(-10.22)$ \\
& $(0.00)$ & $(0.00)$ & $(0.00)$ & $(0.00)$ \\
\hline Q8_4-Not at & $0.207^{* * *}$ & $0.189^{* * *}$ & -0.034 & $-0.362^{* * *}$ \\
\hline
\end{tabular}

\footnotetext{
$1 *$ significant at the $5 \%$ level, ** significant at the $2.5 \%$ level, *** significant at the $1 \%$ level. Second row shows z-statistics and third row shows p-values.
} 


\begin{tabular}{|l|l|l|l|l|}
\hline all concerned & $(8.32)$ & $(13.19)$ & $(-1.62)$ & $(-16.12)$ \\
& $(0.00)$ & $(0.00)$ & $(0.106)$ & $(0.00)$ \\
\hline Q8_5 - Don't & 0.029 & 0.055 & $0.047^{* *}$ & -0.131 \\
know & $(0.89)$ & $(1.07)$ & $(2.00)$ & $(-1.23)$ \\
& $(0.376)$ & $(0.284)$ & $(0.045)$ & $(0.219)$ \\
\hline Q8_6 - No opin- & 0.060 & 0.096 & $0.054^{* * * *}$ & -0.210 \\
ion & $(1.00)$ & $(1.40)$ & $(4.34)$ & $(-1.72)$ \\
& $(0.319)$ & $(0.162)$ & $(0.00)$ & $(0.085)$ \\
\hline
\end{tabular}

Table 2. Marginal effects for willingness to vote for government spending taxpayers' money on climate policies and concern about climate change. Base question Q8_1 Very concerned Compiled by authors.

The second model shows that climate change is not a politically contested issue for the British public, i.e. voting decisions are not based on political parties' positions on climate change. Individuals' political party positions hardly matter for their concern for climate change, although Conservative voters do tend to be slightly less concerned about climate change compared to Labour supporters as indicated in Table 3.

\begin{tabular}{|c|c|c|c|}
\hline \multicolumn{4}{|c|}{$\begin{array}{l}\text { Q52 How would you vote if there were a General Election tomorrow? } \\
\text { Base question - Q52 } 1 \text { Conservatives }\end{array}$} \\
\hline Q52 - 2 Labour & $-0.224^{*}$ & $(-2.38)$ & $(0.017)$ \\
\hline Q52 - 3 Liberal Democrat & -0.142 & $(-1.26)$ & $(0.207)$ \\
\hline Q52 - 4 Scottish National & -0.57 & $(-0.26)$ & $(0.797)$ \\
\hline Q52 - 5 Welsh National & -0.246 & $(-0.87)$ & $(0.386)$ \\
\hline Q52 - 6 Green Party & -0.246 & $(-1.35)$ & $(0.177)$ \\
\hline Q52 - 7 Democratic Party & -0.606 & $(-0.71)$ & $(0.478)$ \\
\hline Q52 - 8 UKIP & 0.035 & $(0.17)$ & $(0.864)$ \\
\hline Q52-9 BNP & -0.380 & $(-1.66)$ & $(0.097)$ \\
\hline Q52 - 10 Other & 0.153 & $(0.60)$ & (0.549) \\
\hline Q52 - 11 Would not vote & -0.125 & $(-1.20)$ & $(0.232)$ \\
\hline Q52 - 12 Undecided & -0.145 & $(-1.76)$ & $(0.078)$ \\
\hline Q52-13 Refused & -0.064 & $(-0.40)$ & $(0.690)$ \\
\hline
\end{tabular}

Table 3. Marginal effects for willingness to vote for political party and concern about climate change. Base question Q52_1 - Voting for Conservatives. Compiled by authors.

These findings point towards the opportunity for political consensus among the political parties given the low danger of 'getting punished' by the electorate for ambitious climate policies (or the lack thereof). Politicians can win those voter groups who are generally concerned about the environment and climate change. Conservative voters however tend to be less concerned about climate change with climate sceptic views on the rise compared to Labour supporters (Pidgeon et al., 2010). 


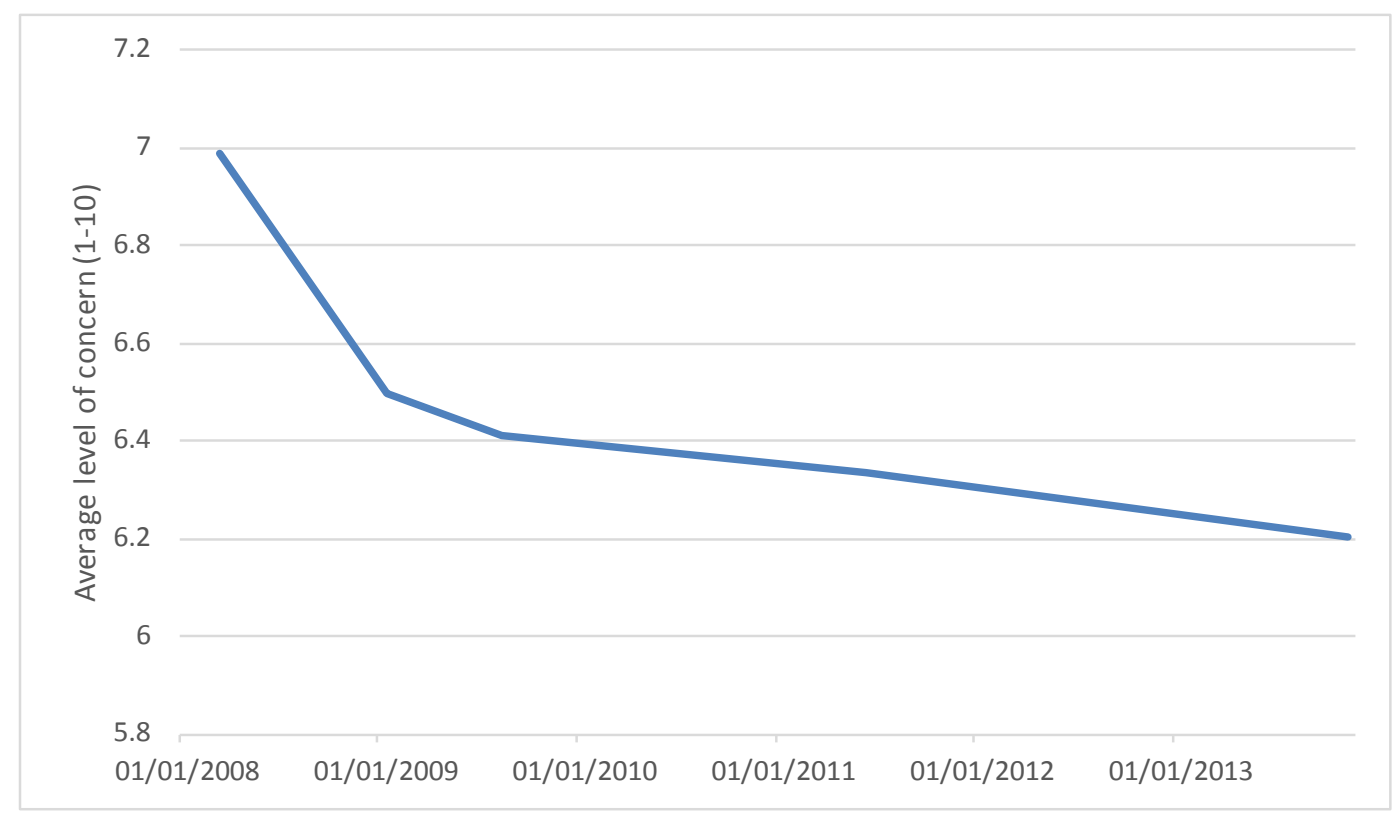

Figure 1: Concern for climate change in the UK 2008-2013 Source: Eurobarometer.

In order to understand how concern has evolved in the UK, the results of the Eurobarometer survey which included questions on the concern for climate change in five separate surveys between 2008 and 2013 are examined. ${ }^{2}$ The Eurobarometer surveys were established in 1973 and consist of surveys of approximately 1000 face-toface interviews per member country on a wide variety of topics. The question asked of participants was:

'And how serious a problem do you think climate change is at this moment? Please use a scale from 1 to 10, where '1' would mean that it is "not at all a serious problem" and '10' would mean that it is "an extremely serious problem"3,

The question was asked in the Eurobarometer surveys of March-May 2008, January-February 2009, August-September 2009, June 2011 and NovemberDecember 2013. From Figure 1 it can be seen that the average level of concern in the UK has fallen sharply since the first survey was undertaken in 2008, falling almost a whole mark from an average approaching to 7 in early 2008, to one just above 6 in late 2013. This decline in concern matches other findings for the EU as a whole

\footnotetext{
${ }^{2}$ The surveys and data are available at: http://ec.europa.eu/public_opinion/index_en.htm.

${ }^{3}$ The question used is identical in all of the surveys used in the dataset with the exception that in the 2008 survey the words 'global warming' were used instead of climate change.
} 
(Scruggs and Benegal, 2013) and for the UK in particular (Lockwood, 2013). This decline in concern was not associated with any significant reductions in the strength of UK policy in this time-period to either the overall policy framework in the shape of the Climate Change Act or its associated carbon budgets, or to the many policies that make up the UK's specific climate policy such as the 2010/11 Energy Acts and the Climate Change Levy. The finding of a strong concern for climate change in 2008, followed by the introduction of the Climate Change Act in 2009, coupled with the finding of a strong correlation between public concern and desire for public action in 2010, help to support the contention that strong public opinion is a necessary precondition for implementing path-dependent climate policy. The finding that the sharp decline in concern was not associated with rolling-back of this policy by 2013 could potentially indicate that the policy framework implemented in the UK was sufficiently locked-in to survive the down-turn in public concern. An alternative explanation is that the down-turn in public concern did not affect the ability to implement policy, although the findings of the first model that public concern was a significant driver of the public's willingness for the government to take action would dispute this, unless government's ability to implement policy was unrelated to the public's willingness for the government to take action.

\section{The relevance of the political system for policy stability}

A number of conditions emerge for policy stability in UK climate policy design relating to the structure of the political system itself. Lock-in, i.e. the immediate irreversibility of policies, is difficult to achieve, as there is no guarantee that the policy will remain following the next general election. Carrying on Labour-induced climate policies to be implemented by the Conservatives required a cross-party consensus on ambitious climate policies, which was facilitated by two factors. None of the parties framed climate policy as a contentious issue in the general election and thus gave voters options to choose between weak or strong climate policies. Instead, both parties presented themselves as committed to climate mitigation (Carter and Jacobs, 2014). This can be understood as a strategy of managing the risk from getting punished for policy choices in the next election (Bertelli and John, 2014). 
Our findings complement Carter and Jacobs’ (2014) findings regarding the importance of a party-political consensus for policy stability within the Westminster political system. Levin et al. (2012) argued that the immediate irreversibility of policies could be achieved via high democratic barriers such as consensus voting. This illustrates the relevance of the political system and its institutional barriers for passing and reversing legislation. Particularly the presidential system in the US with its requirements to pass global climate change treaties such as the Kyoto Protocol through the Senate and House of Representatives with differing political majorities under a strict separation of powers (Bell, 2004) proved a major stumbling block to global action on mitigating climate change in the case of the Kyoto Protocol. In contrast, parliamentary systems such as the UK with their more fluid power sharing between legislature and executive facilitate the emergence of policies given a party majority - yet these policies have fewer 'protective hurdles' to take if the opposition gains power following the next election and decides to dismantle these policies. Furthermore, the election campaign may have been unrelated to climate policy, making policy uncertainty a matter of 'collateral damage' beyond public opinion and democratic demands. This, in turn, influences strategic voting behaviour among voters deeply concerned about climate change (Kedar, 2011). In addition, the electoral system may also exert influence on the level of policy stability attainable, such as the differences between the UK 'first-past-the-post' winner takes it all versus a proportional representation system where the preferences of minority voters are represented more accurately such as in Germany (Vowles, 2004). In the 'public mood', there was no clear-cut link between political preferences and climate change concern, pushing voters with green beliefs and climate concern to one particular party. Consequently, policies with the potential for lock-in must be framed within a noncontentious, non-confrontational party political consensus.

In the case of climate policy in parliamentary systems such as the UK, Germany or in particular smaller EU member states, being embedded into the complex legislative structures within the EU provides a limited backstop if coupled with the danger of 'losing face' through too many policy U-turns and violation of previous commitments. Certain parallels could be drawn to Spilker's (2011) argument on the reputational stakes that influence the compliance of developing countries with environmental standards based on their institutionalised membership in intergovernmental organisations. This points towards the additional relevance of 
supra- and international decision-making forums for national policy formulation with a higher likelihood of consensual decision-making such as in the UNFCCC.

Strong embeddedness in multilevel governance plays a crucial role for achieving and strengthening policy stability considering that climate change affects multiple governance levels ranging from the local via the national and transnational to the global level (Markantoni, 2016; Paavola, 2016; Smedby and Quitzau, 2016). Outcomes on the level of the global climate change negotiations within the UNFCCC are very difficult to achieve given the requirement of unamity among 196+ countries. Yet, once adopted, the 2015 Paris Agreement provides a very strong signal to countries, industries and the investment community that economic growth in the $21^{\text {st }}$ century will be based on decarbonisation and decoupling of GHG emissions from economic activity. This in turn reassures UK-based actors of the importance of the 2008 Climate Change Act to remain in place and deters future governments from going against global commitments (criterion 1 by Levin et al., 2012). Reassurances for the business community and inherent pay-offs from investments particularly in the areas of energy efficiency and cost-competitive renewable energies can be seen as one option to achieve criteria 2, 3 and 4 for stable policies suggested by Levin et al. (2012) as being self-reinforcing with increasing returns and positive feedback. The Carbon Budget provides a good overall objective while remaining flexible on how exactly the targets are achieved, thus also allowing for minor adjustments over time (criterion 5 on adaptability within policy pathways).

The findings on voter support and party-political positions on climate change are interesting if considering how the 2008 UK Climate Change Act emerged. A campaign by Friends of the Earth in 2005 provided an external push of climate change onto the British political agenda. It was the Conservatives under the leadership of David Cameron who pushed for a British climate policy: David Cameron used climate change as a new issue on the agenda to rebrand his party with a view to the 2010 election and thus to end 13 years in opposition. Cameron's calls for a climate change bill coincided with Secretary of State for Environment, Food and Rural Affairs David Milliband's push for climate mitigation in the UK and his support for a 30 per cent GHG emission reduction target of the EU (by 2020 from 1990) instead of only 20 per cent. In addition, an alliance of businesses also asked for robust climate policies to allow for reliable investments in renewable energy infrastructure (Carter 
and Jacobs, 2014). These external pushes from the business community and the issue competition from the Conservatives resulted in reduced opposition within the Labour parties’ ranks. Consequently, UK climate policies became possible due to inter-party competition. Both departed from the 'play it safe and do little' consensus of the early 2000s (Carter, 2006). It was also facilitated by the non-politisation of climate change and in particular the emerging cross-party political consensus to plan, legislate and implement climate change policies even after the opposition party took power following the general election in 2010 (Carter and Jacobs, 2014).

\section{Discussion}

British climate policy to date only displays some characteristics of the level of pathdependency required to achieve policy stability while maintaining ambitious climate mitigation objectives. The key pitfall is the simple reversibility within the Westminster parliamentary political system based on a political parties' majority. Policies can be relatively easily reversed given the absence of constitutional provisions or consensus voting (Levin et al., 2012). Thus, the lock-in effect (criterion 1 for policy stability) remains fairly weak within the UK. There are however a number of safeguards that strengthen policy stability. First, the 2008 UK Climate Change Act is set up as a legally binding commitment, sending a strong signal to future governments that it is intended to serve as the UK's climate flagship policy well into the 2040s, allowing for strengthening of the commitments, but discouraging a weakening of the climate targets. The time period between 2008 and 2016 has already resulted in increasingly powerful vested interests in the form of clean industries benefitting from the regulatory framework and lobbying for its continued stringency (criterion 2 is thus partly fulfilled). Secondly, its firm embeddedness into the European climate strategy (at least for the first decade) and international mitigation targets via the UNFCCC, the Kyoto Protocol and the recent 2015 Paris Agreement however offer the basis for lock-in effects (alternative mechanisms for criterion 1). The carbon budgets provide a certain reliability for the business 
community to make investments in line with the planned $\mathrm{CO}_{2}$ emission reductions, resulting in increasing returns over time as renewable energies improve their costcompetitiveness (criterion 3 fulfilled). The key aspect are vested interests. As an increasing number of industries and employees benefit from the clean technologies and new markets of the 'sharing economy', the support expands to other populations beyond the initial target population (criterion 4 fulfilled). The yet undefined carbon budgets towards 2050 allow for adaptability within the pathway to a low carbon economy, in particular in terms of choosing policy instruments appropriate to the economic situation and technological advances (criterion 5 fulfilled), while allowing flexibility on the policy instruments used to achieve the targets.

Yet, a note of caution is important. First, there is no guarantee that decisions taken by a new government and the re-evaluation of policies in the wake of Brexit will not reverse or abandon current government policy. Second, in the Westminster parliamentary system, lock-in, and with it stable climate policy, requires a stable cross-party political consensus, as otherwise the risk remains that one government's climate policy is reversed once the opposition party takes over following the next general election. Changes to policies are however costly and require short-term wins for those reversing the policies such as the expectation of winning climate sceptic voters versus losing fewer voters with green preferences. This in turn requires the basic assumption that political party positions on climate change influence voting behaviour in the first place. Furthermore, public opinion strongly discounts future benefits as opposed to up-front costs. This means that stable policies should start with low ambitions and be adaptable towards higher ambitions over time, which need to be in line with the future benefits for the public and tax payer. The findings indicate that there is a benefit in stable policies with a path-dependency element as these allow to align initial low costs-low benefits with later higher costs (from more ambitious policies) and higher benefits. They thus break the time-lag of low political acceptability, which is linked to initially ambitious (and costly) policies. 


\section{Conclusion}

Key challenges of 'super-wicked' problems such as climate change call for ambitious policies within stable policy frameworks to be effective. Policy stability requires lockin into a low-carbon economic development trajectory, support from the initial target population that extends to other populations, needs to be self-reinforcing with costs for reversal rising over time while benefits from the policy increase (Levin et al., 2012). There is also a need for adaptability within an overall low-carbon economic development trajectory as new scientific evidence calls for adjustments. To this end, this contribution analysed the framework conditions for stable policies to emerge and remain in place by focusing on the relevance of the political system and public opinion at the example of UK Climate Change Policy.

The UK Climate Change Act 2008 can be considered as a weakly stable policy that meets elements of the path-dependency criteria set out by Levin et al. (2012), in particular via the long-term objective to reduce over 80 per cent of GHG by 2050 and the specified carbon budgets set into legally binding form. The Westminster parliamentary political system however remains vulnerable to major policy shifts and resulting investment instabilities once general elections empower the political opposition or government changes due to the resignation of the Prime Minister. These cases occurred in the UK in 2010, 2015 and 2016. This illustrates the importance of cross-party political consensus to lend policy stability. In 2010, the Conservative/ Liberal Democrat government implemented the Labour-designed Climate Change Act 2008 and agreed on the fourth carbon budget. Until the UK leaves the EU and depending on the negotiations on the future relationship of UK and EU climate policy (and, by extension, the future of the UK Climate Change Act), UK climate policy remains deeply embedded into the EU climate policy package on renewable energies, energy efficiency and the European Emission Trading Scheme. Yet, also outside the EU, the UK made strong commitments under the UNFCCC Kyoto Protocol Phase II (2012-2020) and the 2015 Paris Agreement. The findings of the Eurobarometer public opinion surveys on climate change carried out between 2010 and 2013 indicate 
considerably high (though declining from 6.4 to 6.2, table 3) public concern and support for climate change policies, including a willingness to pay and to spend taxpayer's money. Yet, there is a trend towards declining concern on climate change in the UK with a rise of climate scepticism, in particular among voters supporting the Conservative Party. Together with the power shift in the Conservative Party, the reshuffling of the Department of Energy and Climate Change into the Department of Business, Energy and Industrial Strategy and the withdrawal of the UK from the EU, policy stability is being weakened. It remains to be seen if the 2015 Paris Agreement, a growing lobbying power of the clean tech industry and green investors as well as the legally binding character of the carbon budgets provide sufficient policy stability for UK climate change policy to prevail.

\section{References}

Balme R, Qi Y. 2014. Multi-Level Governance and the Environment: Intergovernmental Relations and Innovation in Environmental Policy. Environmental Policy and Governance 24: 147-154.

Barnes W, Gartland M, Stack, M. 2004. Old Habits Die Hard: Path Dependency and Behavioural Lock-In. Journal of Economic Issues 38(2): 371-378.

Bauer MW, Jordan A, Green-Pedersen C, Heritier A. 2012. Dismantling Public Policy. Preferences, Strategies, and Effects. Oxford: Oxford University Press.

Baumgartner FR, Breunig C, Green-Pedersen C, et al. 2009. Punctuated Equilibrium in Comparative Perspective. American Journal of Political Science 53(3): 603620.

Bell LC. 2004. Following the Leaders or Leading the Followers? The US President's Relations with Congress. The Journal of Legislative Studies 10(2-3): 193-205.

Berkhout, F. 2002. Technological Regimes, Path Dependency and the Environment. Global Environmental Change 12: 1-4.

Bernstein S, Cashore B. 2007. Can Non-State Global Governance Be Legitimate? An Analytical Framework. Regulation \& Governance 1: 347-371.

Bertelli AM, John P. 2014. Public Policy Investment: Risk and Return in British Politics. British Journal of Political Science 43: 741-773. 
Booth A, Choudhary R. 2013. Decision Making under Uncertainty in the Retrofit Analysis of the UK Housing Stock: Implications for the Green Deal. Energy and Buildings 64: 292-308.

Brandenburg H, Van Egmond M. 2011. Pressed into Party Support? Media Influence on Partisan Attitudes during the 2005 UK General Election Campaign. British Journal of Political Science 42(2): 441-463.

Carey JM, Hix S. 2011. The Electoral Sweet Spot: Low-Magnitude Proportional Electoral Systems. American Journal of Political Science 55(2): 383-397.

Carter, N. 2006. Party Politicisation of the Environment in Britain. Party Politics 12(6): 747-767.

Carter N, Jacobs M. 2014. Explaining Radical Policy Change: The Case of Climate Change and Energy Policy Under the British Labour Government 2006-10. Public Administration 92(1): 125-141.

Eurobarometer Survey Data 2008-2013. European Commission. http://ec.europa.eu/public_opinion/index_en.htm.

Favretto N, Stringer LC, Dougill AJ. 2015. Towards Improved Policy and Institutional Coherence in the Promotion of Sustainable Biofuels in Mali. Environmental Policy and Governance 25(1): 36-54.

Foxon, TJ. 2013. Transition Pathways for a UK Low Carbon Electricity Future. Energy Policy 52: 10-24.

Gifford L, Luedecke G, McAllister L, et al. (2016). World Newspaper Coverage of Climate Change or Global Warming, 2004-2016. Center for Science and Technology Policy Research, Cooperative Institute for Research in Environmental Sciences, University of Colorado, Web. 25.07.2016.

http://sciencepolicy.colorado.edu/icecaps/research/media_coverage/world/index. html.

Gravey V, Jordan A. 2016. Does the European Union Have a Reverse Gear? Policy Dismantling in a Hyperconsensual Polity. Journal of European Public Policy 23(8): 1180-1198.

Hysing E. 2014. A Green Star Fading? A Critical Assessment of Swedish Environmental Policy Change. Environmental Policy and Governance 24: 262-274.

Jordan A, Matt E. 2014. Designing Policies That Intentionally Stick: Policy Feedback in a Changing Climate. Policy Sciences 47(3): 227-247.

Kedar O. 2011. Voter Choice and Parliamentary Politics: An Emerging Research Agenda. British Journal of Political Science 42(3): 537-553. 
Kingdon JW. 1995. Agendas, Alternatives, and Public Policies. Glenview, IL: Longman.

Koch J, Eisend M, Petermann A. 2009. Path Dependence in Decision-Making Processes: Exploring the Impact of Complexity under Increasing Returns. Business Research 2(1): 67-84.

Levin K, Cashore B, Bernstein S, Graeme Auld G. 2012. Overcoming the Tragedy of Super Wicked Problems: Constraining Our Future Selves to Ameliorate Global Climate Change. Policy Sciences 45: 123-152.

Liang J, Fiorino DJ. 2013. The Implications of Policy Stability for Renewable Energy Innovation in the United States, 1997-2009. Policy Studies Journal 41(1): 97118.

Lockwood M. 2013. The Political Sustainability of Climate Policy: The Case of the UK Climate Change Act. Global Environmental Change 23(5): 1339-1348.

Mahzouni A. 2015. The 'Policy Mix’ for Sustainable Urban Transition: The City District of Hammarby Sjöstad in Stockholm. Environmental Policy and Governance 25(4): 288-302.

Markantoni M. 2016. Low Carbon Governance: Mobilizing Community Energy through Top-Down Support? Environmental Policy and Governance 26(3): 155169.

Nachmany M, Fankhauser S, Townshend T, et al. 2014. A Review of Climate Change Legislation in 66 Countries. London. Globe International and LSE.

O’Neill K, Weinthal E, Suiseeya KRM, et al. 2013. Methods and Global Environmental Governance. Annual Review of Environment and Resources 38: 441-471.

Paavola J. 2016. Multi-Level Environmental Governance: Exploring the Economic Explanations. Environmental Policy and Governance 26: 143-154.

Pidgeon N, A Spence, and W. Poortinga. 2010. Public Perceptions of Climate Change and Energy Futures in Britain, 2010. Colchester, Essex: UK Data Archive. http://dx.doi.org/10.5255/UKDA-SN-6581-1.

Sabatier PA. 1998. The Advocacy Coalition Framework: Revisions and Relevance for Europe. Journal of European Public Policy 5(1): 98-130.

Scruggs L, Benegal S. 2013. Declining public concern about climate change: Can we blame the great recession? Global Environmental Change 22(2): 505-515. doi:10.1016/j.gloenvcha.2012.01.002

Skaerseth J, Wettestad J. 2009. The Origin, Evolution and Consequences of the EU Emissions Trading System. Global Environmental Politics 9(2): 101-122. 
Smedby N, Quitzau M-B. 2016. Municipal Governance and Sustainability: The Role of Local Governments in Promoting Transitions. Environmental Policy and Governance. (Online First): 1-14. doi:10.1002/eet.1708.

Spilker, G. 2011. Helpful Organizations: Membership in Inter-Governmental Organizations and Environmental Quality in Developing Countries. British Journal of Political Science 42(2): 345-370.

Vowles J. 2004. Electoral Systems and Proportional Tenure of Government: Renewing the Debate. British Journal of Political Science 34(1): 166-179.

Wamsler C. 2016. From Risk Governance to City-Citizen Collaboration: Capitalizing on Individual Adaptation to Climate Change. Environmental Policy and Governance 26: 184-204. 